\title{
Teaching Circuits to New Generations of Engineers
}

\author{
Ljiljana Trajković \\ Simon Fraser University \\ Vancouver, British Columbia, Canada \\ $\{$ ljilja\}@cs.sfu.ca
}

\begin{abstract}
Understanding circuits is fundamental to electrical engineering and continuing to offer courses in theory and applications of electric circuits to new generations of engineering students remains an important part of any engineering curriculum. Attracting new generations of students to circuits is a challenging task that calls for new approaches, methodologies, and projects that will appeal to current generations of both educators and students. Designing these new tools and making them freely available to educators is an important step in eliciting renewed interest in circuits.
\end{abstract}

\section{INTRODUCTION}

Many of us enjoy teaching courses in electric circuits and find working with students gratifying. We also believe that providing students with a solid theoretical background greatly improves their ability to solve a variety of practical engineering problems. National institutions have recognized the need for improving engineering education [1]. Attracting the best students to engineering programs end eliciting their interest to circuits courses has been also subject of a number of ongoing debates over the past two decades [2]-[8].

Current engineering programs offer a number of options such as electronic engineers, computer engineers, bioengineers, and mechatronics majors. These programs may require that circuits courses are designed for specific engineering majors. Not all students enrolled in engineering programs will become circuit designers and, hence, may need circuits courses carefully tailored to fit a program's specific curricula.

The "cookbook" approach offered by a myriad of textbooks available in our bookstores (at a hefty price) may not be serving future electrical engineers well. Lectures, tutorials, and laboratories are often supplemented by software tools such as MATLAB and SPICE to enhance understating of the theory taught. Presentation styles and course delivery have made a full circle: from blackboard to overhead projectors to PowerPoint slides and back to the whiteboard. Communication tools such as web pages, online notes, electronic handouts, audio recordings of lectures, use of examples from industry, fun exercises and puzzles, and endless stream of email correspondence are only part of course deliveries. Presentation styles and delivery are often enhanced by good textbook supplements (master slides, tutorial problems, solution manuals) when available. There is also demand for new tutorials, video-taped lectures, educational games, design kits, fun and motivational lectures, and online content.

In many engineering departments, circuits courses are considered to be service courses. They are often taught by sessionals and instructors as a service to the department. As such, these instructors are often unmotivated and can hardly generate students' enthusiasm. More senior faculty teaching circuits courses often have their research interests in areas not related to circuit theory and/or circuit design. Furthermore, lack of industrial experience often deprives instructors from appreciating the importance of practical applications in engineering education.

\section{CASe Study: Engineering Program at Simon FRASER UNIVERSITY}

My teaching portfolio, for example, includes teaching courses in circuit analysis, VLSI design, and courses in computer-aided tools for analog circuit simulation. In my teaching, I emphasize the importance and the impact of circuit theoretic results on the IC circuit design and the development of new software tools for circuit analysis and simulation. When teaching my graduate course in nonlinear circuits, I emphasize both rigor and practical applications. I taught a number of courses at several academic institutions. At Simon Fraser University (SFU), I currently teach basic undergraduate circuits courses that consist of lectures, tutorials, and laboratories. In the mid 90s, at UC Berkeley, I taught an innovative undergraduate course on introduction to real-time digital systems. I have also developed and taught a graduate course in the theory, analysis, and simulation of nonlinear circuits. In mid 80's at UCLA, I taught courses in classical circuit analysis and synthesis. Even though they have been long abandoned in current engineering curricula, performance requirements of modern high-speed, low-power analog circuit designs require an approach that embraces a close relationship between circuit theory and circuit design.

School of Engineering Science at SFU offers two classical undergraduate courses in electric circuits. These courses are offered to second and third year students. SFU follows trimester system (three terms per calendar year) and each term lasts thirteen weeks. There are weekly homework assignments and the midterm and final examinations. In addition to three-hour lectures per week, one-hour tutorials offered weekly for the two basic circuits courses deal with solving analytical problems. Both undergraduate circuits courses have laboratory components and students are expected to submit written laboratory reports. The School follows the 24/7 openlaboratory model. There is no required textbook. Several textbook are recommended [9]-[13]. A large number of textbooks [14]-[21] and references related to filter design [22]-[25] 
are made available through the University Library reserves. Occasionally, a course in nonlinear circuits is offered to senior undergraduate and graduate students as a special topics course [26]-[30]. There are weekly homework assignments, two short midterm examinations, and a final research project.

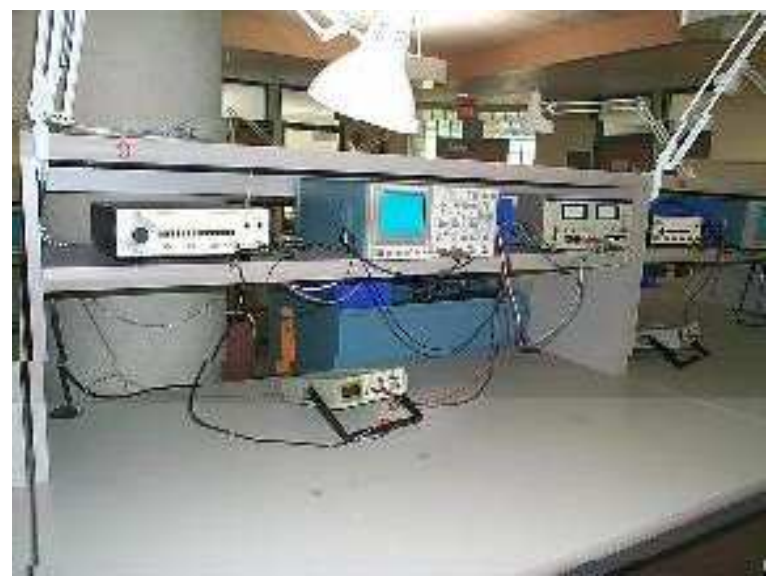

Fig. 1. Typical laboratory bench with test equipment.

\section{First Course: Electric Circuits I}

The first course in electric circuits deals with elementary concepts and analysis tools. The course pre-requisites are two first year physics courses and the course co-requisites are two second year mathematics courses. This course is a prerequisites for undergraduate courses in electronic devices and microelectronics. It covers traditional topics that include:

- Circuit elements: voltage sources, current sources, resistors, diodes, transistors.

- Kirchhoff current (KCL) and voltage (KVL) laws.

- Operational amplifiers (op-amps): ideal models of opamps; inverting and non-inverting op-amps; the op-amp and a dependent source.

- Circuit analysis techniques: nodal and loop (mesh) analysis: linearity, superposition, and source transformations; Thevenin and Norton theorems; maximum power transfer.

- First order circuits: inductors and capacitors; response of RL and RC circuits.

- Second order circuits: series and parallel RLC circuits; step response.

- Sinusoidal steady-state analysis: sinusoidal response; phasor analysis; real, active, and complex power.

- AC power: power in time domain; power in sinusoidal steady state; average or real power; reactive power; summary of $\mathrm{AC}$ power in $\mathrm{R}, \mathrm{L}$, and C; exchange of energy between an inductor and a capacitor; complex power, apparent power, and power triangle; parallel-connected networks; power factor improvement; maximum power transfer.

- Polyphase circuits: introduction; two-phase systems; three-phase systems; wye and delta systems; phasor voltages; balanced delta-connected loads; balanced fourwire; wye-connected loads; equivalent wye and deltaconnections; single-line equivalent circuit for balanced three-phase loads; unbalanced delta-connected load; unbalanced wye-connected load; three phase power; power measurement.

\section{A. Electric Circuits I Laboratories}

- Lab bench orientation: Part 1, Power Supply and Digital Multimeter and Part 2, Function Generator and Oscilloscope.

- Lab 1, KCL and KVL: Use a simple circuit to verify KVL by showing that the sum of voltages around the given loop is zero and to verify KCL by showing that the currents entering a node sum to zero.

- Lab 2, Op Amp: Using the circuits with Op Amp TL071 study op amps and characterize their behavior.

- Lab 3, RL and RC circuits: Wind (and test) your own inductor, which you will also use in the AM radio project in a subsequent lab. Investigate the properties of capacitors by making a simple capacitor and by designing and testing filters and a simple capacitive switch.

- Lab 4, RLC circuits: Study a series RLC circuit from both a time-domain and frequency-domain perspective and investigate topics such as: damping, overshoot, rise time, frequency of oscillation, settling time, resonance, bandwidth, and the $\mathrm{Q}$ factor.

- Lab 5, AM radio demo: Build and test a simple AM (amplitude modulation) receiver. Design a tuner, an AM detector, and an audio amplifier. The audio amplifier may be used to drive a pair of ordinary headphones. The handout outlines the minimum number of components needed to build the receiver:

\section{SECond Course: Electric Circuits II}

The second course in electric circuits is intended to enhance the knowledge of students in the area of electric circuits and to further develop their analytical skills. The course pre-requisite is the first course in electric circuits. It covers:

- Analysis of circuits in the time domain: review of differential equation analysis of linear circuits; treatment of initial conditions; zero state and zero input responses; properties of more general linear time invariant systems in continuous time; convolution, unit impulse response.

- Laplace transform analysis of circuits: the Laplace transform and its inversion by partial fractions; properties: multiplication-convolution, differentiation, initial and final value theorems; circuits in the $s$-domain: transfer function, impedance, circuit reduction, initial conditions; series and parallel decompositions; pole-zero diagrams related to time domain behavior.

- Frequency response, filters, and resonance: frequency response; high-pass and low-pass networks; half-power frequencies; frequency response from pole-zero locations and Bode plots; bandpass filters and resonance; natural frequency and damping ratio. RLC series circuit; series 
resonance; quality factor; RLC parallel circuit; parallel resonance; practical LC parallel circuit; series-parallel conversions; locus diagrams.

- Filter design: filter classes (Butterworth, Chebyshev); implementation diagrams, quadratic sections; state variable description; active filter implementation: Sallen-Key and state variable filters; other active filter configurations.

- Mutual inductance and transformers: mutual inductance; coupling coefficient; analysis of coupled coils; dot rule energy in a pair of coupled coils; conductively coupled equivalent circuits; linear transformer; ideal transformer; autotransformer; reflected impedance.

- Two-Port networks: terminals and ports, z-parameters; t-equivalent of reciprocal networks. y-parameters; piequivalent of reciprocal networks; applications of terminal characteristics; conversion between $\mathrm{z}$ and y parameters; $\mathrm{h}$ and $\mathrm{g}$ parameters; transmission parameters; interconnecting two-port networks; choice of parameter type.

\section{A. Electric Circuits II Laboratory}

The laboratory exercise deals with the design and implementation of an active filter. The students are asked to design a low pass filter for telephone speech signals that have bandwidth of $300-3,400 \mathrm{~Hz}$. The filter is to be used to suppress interference by attenuating interference signals by at least $30 \mathrm{~dB}$ starting at $11 \mathrm{kHz}$. The telephone signal should not be attenuated more than $0.5 \mathrm{~dB}$. Students are given the laboratory assignment and the instructions early in the trimester:

- Design: Examine Butterworth and Chebyshev filter realizations that meet the specifications. Plot frequency responses using MATLAB. Select the most appropriate filter type, order, and filter parameters. Design the filter using Sallen-Key stages with an overall gain (output voltage/input voltage) in the range 2 to 3. Simulate your design using PSPICE. Build the filter circuit, test it, and compare its performance to the specifications and to PSPICE predictions.

- Parts: The kit with parts contains: quad op amp: TL074CP; various resistors ( $\mathrm{k} \Omega$ range); capacitors in the $\mathrm{nF}$ range: $22 \mathrm{nF}$ caps, quantity $4 ; 10 \mathrm{nF}$ caps, quantity 4; $3.3 \mathrm{nF}$ caps, quantity $4 ; 1 \mathrm{nF}$ caps, quantity 4 ; power supply isolation capacitors $(0.1 \mu \mathrm{F}$, quantity 4$)$.

- Test measurements: Input a sinusoidal wave of $2 \mathrm{~V}$ peakto-peak and plot the frequency response (magnitude and phase Bode plots) for the range from $10 \mathrm{~Hz}$ to $1 \mathrm{MHz}$. Compare your results with PSPICE simulations.

- Design notes: Choose resistors so that the overall gain is not so high that the voltages exceed the power rails. Use capacitors above $100 \mathrm{pF}$, preferably in the $\mathrm{nF}$ range. Use clean voltage supplies (i.e., $0.1 \mu \mathrm{F}$ capacitors at $+\mathrm{Vcc}$ and $-\mathrm{Vcc}$, where $\mathrm{Vcc}=12 \mathrm{~V}$ ).

- Optional: When you have your circuit working, try several optional steps. Filter speech and noise. There are some black (beige, actually) boxes available with amps, summers, a noise source, and tunable switched capacitor filters. Find a microphone, add some noise with bandwidth of $20 \mathrm{kHz}$, and listen to the result with and without the filter that you built. Redesign a second order stage with very small capacitors $(10 \mathrm{pF})$. You will most likely find your circuit oscillating, instead of amplifying.

- Lab report: Include title page and a maximum of additional ten pages. Describe your design and the performance of your implementation. Explain differences between your expectations and the actual filter performance.

\section{Additional Course Resources}

The entire course material is available online. Course web pages contain links to homework assignments, laboratory exercises, and supplementary references. Each course lecture is audio recorded and these recordings are made available shortly after each lecture to students enrolled in the course.

\section{A. Puzzles and Games}

A variety of puzzles are posted on the course website. Students are given extra credit for submitting correct solutions.

- Puzzle 1: Select the internal resistance of a source so that it delivers maximum power to a resistive circuit.

- Puzzle 2: Use the simplest model for a diode and construct a simple circuit so that KCL and KVL equations have no solutions.

- Puzzle 3: Find the voltage and current in the middle of a ladder circuit made of resistors $1.0 \mathrm{Ohm}$ each.

- Puzzle 4: Finds the equivalent resistance seen at the input port of an infinite ladder circuit with a common ground node. All resistors have the same resistance.

- Puzzle 5: Find the resistance seen between any two adjacent nodes in the middle of an infinite maze of resistors $1 \mathrm{Ohm}$ each.

\section{Graduate Course: Special Topics in Theory, ANALysis, AND Simulation OF NONLINEAR CiRCUITS}

This is a research oriented graduate course in nonlinear circuits. The course aims to provide insights and understanding of complex static and dynamic behavior of circuits consisting or bipolar and MOS transistors. Topics include: global properties of electronic components, properties of nonlinear circuit equations, existence and uniqueness of dc operating points, stability of operating points and the occurrence of bistability, methods for computing solutions to dc, ac, and transient circuit equations, homotopy methods for finding such solutions and their software implementations. Emphasizes is given to the relationship of circuit theory to circuit design and its usefulness in practical applications. Students are introduced to various theoretical approaches and numerical methods for analyzing nonlinear electronic circuits.

The course pre-requisites are undergraduate courses in electric circuits, electronic devices, microelectronics, and a first course in linear algebra. 


\section{A. Graduate Research Projects}

A final research project is an important component of the course. Software tools such as MATLAB and PSPICE are used for circuit simulations. Sample projects:

- Stimulations of negative resistance circuits

- Analyzing stability of nonlinear circuits

- Computing dc operating points of nonlinear circuits

- Analysis, modeling, and design of an IGBT-based power converter.

\section{CONCLUSION: LESSONS LEARNED}

School of Engineering Science at SFU offers a five-year undergraduate program in engineering. The program is highly ranked among the comprehensive Universities in Canada. However, many students are entering the engineering program without having necessary mathematical background and analytical skills to excel and enjoy the subjects taught.

Changing undergraduate engineering curriculum to adopt new approaches to teaching circuits is a difficult task. The curriculum already contains a large number of required courses, which leaves little room for implementing desired changes such as, for example, offering separate laboratory courses as a follow-up to lecture-intensive courses in circuits.

Attracting students to take circuits courses and motivating them to complete these courses is an essential component of teaching the course. Very early in the trimester, simple examples of electronic components (diodes, nonlinear resistor, op-amps, and transistors) are used to illustrate modeling circuits and to emphasize that linear circuits are only an approximation of electric and electronic elements. Examples employing linear op-amps are then used to introduce various linear analysis methods. Early exposure to software tools such as MATLAB and SPICE provides a valuable complement to analysis. The analytical and simulation results are then confirmed by laboratory measurements.

Feedback received from students indicates that majority of current undergraduate students find the circuits courses difficult and demanding. Past experiences with choosing a variety of textbooks showed that almost any of the textbooks would prove adequate. More important was the delivery of lectures, selection of topics covered, choice of assignments and examination questions, and quality of the laboratory equipment. Students overwhelmingly enjoyed having laboratory exercises and course projects, which they often complete by working in teams of two or three. Such laboratories, however, should be properly maintained and equipped.

In closing and looking forward, if we wish to generate interest in circuits among the incoming engineering students, we need to do a better job of promoting the profession by: providing betters teaching tools and delivery methods, combining circuit theory courses with laboratory exercise, illustrating the application of circuits in fields relevant to environment, biotechnology, medicine, recognizing and rewarding teaching circuits courses, and doing a better job in sharing our enthusiasm for the engineering profession.

\section{ACKNOWLEDGMENT}

Material used in this paper emanated from a variety of undergraduate and graduate circuits courses and contributions from numerous colleagues who currently teach similar courses.

\section{REFERENCES}

[1] National Science Foundation, Moving Forward to Improve Engineering Education, NSB-07-122, Nov. 19, 2007.

[2] R. Rohrer, "Taking circuits seriously," IEEE Circuits and Devices Magazine, vol. 6, no. 4, pp. 27-31, July 1990.

[3] Y. Tsividis, "Some thoughts on introducing today's students to electrical engineering," IEEE CAS Newsletter, vol. 9, no. 1, p. 1, 6-7, March 1998.

[4] Y. Tsividis, "Teaching circuits and electronics to first-year students," Proc. IEEE Int. Symp. Circuits and Systems, Monterey, CA, May/June 1998, pp. 424-427.

[5] Y. Tsividis, "Turning students on to circuits," IEEE Solid-State Circuits Newsletter, pp. 6-9, January 2008.

[6] CAS Education Workshop 2008: Views, Experience, and Prospects for Education in Circuits and Systems, Seattle, WA, May 2008.

[7] J. Vandewalle, Lj. Trajković, and S. Theodoridis, "Introduction and outline of the special issue on circuits and systems education: experiences, challenges, and views," IEEE Circuits and Systems Magazine, vol. 9, no. 1, pp. 27-33, First Quarter 2009.

[8] J. Vandewalle and T. Ogunfunmi, Circuits \& Systems (CAS) Concept Inventory, Special Session, Proc. IEEE Int. Symp. Circuits and Systems, Paris, France, May/June 2010, pp. 2800-2816.

[9] N. Balabanian, Electric Circuits. New York, NY: McGraw Hill, 1994.

[10] R. A. DeCarlo and P.-M. Lin, Linear Circuit Analysis: Time Domain, Phasors, and Laplace Transforms Approaches, 2/e, Oxford University Press, Cambridge, MA, 2001.

[11] J. W. Nilsson and S. A. Riedel, Electric Circuits Revisited and PSpice Supplement Package, 9/e, Prentice Hall, Upper Saddle River, NJ, 2011.

[12] M. Reed and R. Rohrer, Applied Introductory Circuit Analysis. Upper Saddle River, NJ: Prentice Hall, 1999.

[13] R. E. Thomas and A. J. Rosa, The Analysis and Design of Linear Circuits, 6/e. New York, NY: John Wiley, 2009.

[14] C. K. Alexander and M. N. O. Sadiku, Fundamentals if Electric Circuits 3/e. New York, NY: McGraw Hill, 2007.

[15] A. M. Davis, Linear Circuit Analysis. Boston, MA: PWS Publishing Co., 1998.

[16] C. A. Desoer and E. S. Kuh, Basic Circuit Theory. New York, NY: McGraw-Hill, 1969.

[17] R. C. Dorf and J. A. Svoboda, Introduction to Electric Circuits, 4/e. New York, NY: John Wiley \& Sons, 1998.

[18] J. Edminster and M. Nahvi, Schaum's Electronic Tutor, Electric Circuits, 3/e. New York, NY: McGraw Hill, 1996.

[19] S. Franco, Electric Circuits Fundamentals. Cambridge, MA: Oxford University Press, 1995.

[20] J. D. Irwin and R. M. Nelms, Basic Engineering Circuits Analysis, 10/e. New York, NY: John Wiley and Sons, 2011

[21] H. W. Jackson, D. Temple, and B. Kelly, Introduction to Electric Circuits, 8/e. Cambridge, MA: Oxford University Press, 2008.

[22] G. C. Temes and S. K. Mitra, Modern Filter Theory and Design. New York, NY: John Wiley and Sons, 1973.

[23] A. S. Sedra and P. O. Brackett, Filter Theory and Design: Active and Passive. Champaign, IL: Matrix Publishers, 1978.

[24] L. P. Huelsman and P. E. Allen, Introduction to the Theory and Design of Active Filters. New York, NY: McGraw Hill, 1980.

[25] R. W. Daniels, Approximation Methods for Electronic Filter Design. New York, NY: McGraw Hill, 1974.

[26] N. Balabanian and T. A. Bickart, Electrical Network Theory. New York, NY: John Wiley and Sons, 1969.

[27] L. O. Chua, C. A. Desoer, and E. S. Kuh, Linear and Nonlinear Circuits. New York, NY: McGraw-Hill, 1987.

[28] M. Hasler and J. Neirynck, Nonlinear Circuits. Norwood, MA: Artech House, 1986.

[29] A. N. Willson, Jr., Editor, Nonlinear Networks. New York, NY: IEEE Press, 1975.

[30] Lj. Trajković and A. N. Willson, Jr., "Theory of dc operating points of transistor networks," Int. J. of Electronics and Communications, vol. 46 , no. 4, pp. 228-241, July 1992. 